\title{
Time trends of neonatal mortality by causes of death in Shenyang, 1997-2014
}

\author{
Qi-Jun Wu${ }^{1}$, Li-Li Li ${ }^{2}$, Jing $\mathbf{L i}^{3}$, Chen Zhou ${ }^{4}$, Yan-Hong Huang ${ }^{3}$ \\ ${ }^{1}$ Department of Clinical Epidemiology, Shengjing Hospital of China Medical University, Shenyang, China \\ ${ }^{2}$ Department of children's health prevention, Shenyang Women and Children Health Care Centre, Shenyang, China \\ ${ }^{3}$ Department of science and education, Shenyang Women and Children Health Care Centre, Shenyang, China \\ ${ }^{4}$ Department of information statistics, Shenyang Women and Children Health Care Centre, Shenyang, China \\ Correspondence to: Qi-Jun Wu, e-mail: wuqj@sj-hospital.org \\ Li-Li Li, e-mail: lililishenyang@sina.com
}

Keywords: annual percent change, neonatal mortality rate, Shenyang, trend

Received: November 24, 2015

Accepted: February 09, 2016

Published: February 24, 2016

\section{ABSTRACT}

To investigate the rate and time trends of neonatal mortality from 1997 to 2014 in Shenyang, which were previously rarely reported upon by developing countries, data on 4719 neonatal deaths (0-28 days) and 970,583 live births from the Shenyang Women and Children Health Care Centre were analyzed. Neonatal mortality rates (per 1000 live births), percent change, and annual percent change (APC) were calculated. During the observation period, neonatal mortality in Shenyang significantly decreased by $\mathbf{7 . 0 4 \%}, \mathbf{8 . 3 3} \%$, and $5.35 \%$ per year overall, in urban and rural areas, respectively. When grouped by category of neonatal death, the time trends of three categories showed statistically significant decreases: congenital malformations $(A P C=-9.97 \%)$, diseases of the perinatal period $(A P C=-6.04 \%)$, and diseases of the respiratory system (APC $=-\mathbf{8 . 5 2} \%$ ). Congenital malformations, diseases of the respiratory system, and diseases of the nervous system and sense organs were the three major contributors to the aforementioned decreasing trend, which accounted for $\mathbf{5 8 . 7 1 \%}$ in overall areas. Among selective causes of neonatal death, the neonatal mortality rates of pneumonia, congenital heart disease, preterm birth and low birth weight, birth asphyxia, and intracranial hemorrhage of the newborn significantly decreased $7.87 \%, 7.32 \%, 2.47 \%, 11.04 \%$, and $10.68 \%$ per year, respectively. In summary, neonatal mortality rates decreased in Shenyang during the 17-year study period. Future studies are warranted to further investigate the factors contributing to the neonatal mortality trends in China.

\section{INTRODUCTION}

Recent data from the United Nations Children's Fund (UNICEF), entitled, A Promise Renewed: 2015 Progress Report demonstrated that since 2000, when governments committed to achieving the Millennium Development Goals (MDGs), the lives of 48 million children under the age of five have been saved [1]. Additionally, in contrast to more than 12 million children who died in 1990, 6.6 million children died before reaching their fifth birthday in 2012, which was a sharp decrease. However, these results are still insufficient when compared to one of the most prominent goals for 2015 (MDG-4), which aims to reduce the child mortality rate by two-thirds from the level reported in 1990 [2].

The neonatal mortality rate is an important indicator used for determining the effectiveness of public health issues, including maternal and child health care services as well as for comparing countries with respect to welfare initiatives [3]. It allows researchers to monitor time and territorial trends in mortality, and consequently, to plan and introduce organizational changes to the health care system [4]. The neonatal mortality rates varied in most countries. In general, neonatal mortality rates are high in Africa and South-Central and Western Asia; intermediate in Eastern Asia, South America, the Caribbean, and 
Australia/New Zealand; and low in North America and Europe [5]. Besides effective medical technology, better access to pre- and postnatal care for all socioeconomic groups and better nutrition [6], the factors that contribute to the international variation in neonatal mortality rates largely stem from differences in the development levels of these countries. Similarly, in China, a wide gap exists in terms of people's income and health status between urban and rural areas and the gap explains the regional differences in children's health status and survival between urban and rural areas [7]. During the last year there were attempts to reach the 2015 MDG deadline on reducing child mortality as well as to provide valuable evidence from developing countries; therefore, we carry out this study to analyze the rate and time trends of neonatal mortality in Shenyang on the basis of a relatively long observation period (1997-2014), with special attention paid to stratifying these results by areas.

\section{RESULTS}

During the 17-year interval, there were 970,583 live births and 4719 neonatal deaths in Shenyang (Table 1). When stratified by areas, the neonatal mortality rates of urban areas were significantly lower than that of rural areas (3.67 versus 6.68 per 1000 live births). Figure 1 visually depicts the time trend and the overall neonatal mortality rate in Shenyang during the time period 1997-2014. The overall neonatal mortality rate was 4.86 per 1000 live births (Table 2). The overall mortality of neonate significantly decreased by $75.34 \%$ from 7.57 to 1.87 per 1000 live births, or $7.04 \%$ per year $(95 \% \mathrm{CI}=-8.60 \%--5.45 \%)$. When stratified by urban and rural areas, the neonatal mortality rate has decreased systematically by $8.52 \%(95 \%$ CI $=-9.67 \%--7.34 \%$ ) in urban areas, and slightly more slowly in rural areas with APC $=-5.26 \%(95 \%$ $\mathrm{CI}=-6.85 \%--3.64 \%)($ Table 3$)$.

\section{Causal categories of neonatal death}

Casual categories of neonatal death and time trends were shown in Table 2. Neonatal mortality rates decreased significantly in 1997-2014 in the following categories: congenital malformations $(\mathrm{APC}=-9.97 \%, 95 \%$ $\mathrm{CI}=-12.04 \%--7.84 \%)$, diseases of the perinatal period $(\mathrm{APC}=-6.04 \%, 95 \% \mathrm{CI}=-7.20 \%--4.81 \%)$, and diseases of the respiratory system $(\mathrm{APC}=-8.52 \%$, $95 \%$ CI $=-12.31 \%--4.55 \%)$. The time trends of other casual categories of neonatal death showed nonstatistical significance. Similar decreasing patterns were also observed in Table 3, which were stratified by urban and rural areas. The contribution rates of each category of death causes were provided in Table 4. Congenital malformations, diseases of the respiratory system, and diseases of the nervous system and sense organs were the three major contributors to the aforementioned decreasing trend, which accounted for $58.71 \%$ in urban and rural areas. Notably, diseases of the nervous system and sense organs were the second major contributors to the decreasing trend of neonatal mortality among urban areas, being responsible for $17.71 \%$ of the decrease. In contrast, this cause of neonatal death was the smallest contributor to the decreasing trend of neonatal mortality among rural areas, being responsible for $4.66 \%$ of the decrease. Figure 2 demonstrated the proportional causal categories of neonatal death.

\section{Selective causes of neonatal death}

Selective causes of neonatal death and time trends were demonstrated in Table 5. Except for septicemia and accidental asphyxia, the time trends of other selective causes of neonatal death showed statistically significant decreases. For example, between 1997 and 2014, the neonatal mortality rates of birth asphyxia, intracranial hemorrhage of the newborn, and pneumonia significantly decreased by $-11.04 \%, 10.68 \%$, and $-7.87 \%$ per year, respectively. When stratified by urban and rural areas, similar patterns were still observed (Table 6).

\section{DISCUSSION}

During the 17 years observational period, we observed a considerable decrease in neonatal mortality from 7.57 to 1.87 per 1000 live births, or $7.04 \%$ per year. Notably, the decreasing trend was slightly stronger in urban areas $(8.52 \%$ per year) than rural areas $(5.26 \%$ per year). Congenital malformations, diseases of the respiratory system, and diseases of the nervous system were the three major contributors to the aforementioned decreasing trend, which accounted for $58.71 \%$ in urban and rural areas. Among selective causes of neonatal death, significant decreasing trends were also observed in pneumonia, congenital heart disease, birth asphyxia, and intracranial hemorrhage of the newborn, as well as stratified by urban and rural areas.

The first and second leading cause of neonatal mortality in Shenyang at the present time is diseases of the perinatal period and congenital malformations. Deaths due to diseases of the perinatal period and congenital malformations have decreased from about 4.13 to 1.19 per 1000 live births and 2.49 to 0.26 per 1000 live births in the period between 1997 and 2014 in urban and rural areas, respectively (Table 1), which might be attributed to the big advances in obstetrics and neonatology during this period. The introduction and rapid dissemination of sonographic investigations during pregnancy and the subsequent changes in obstetric management of high-risk births are probably the main reasons for this improvement. In addition, pregnancies with prenatal problems were detected earlier and more often and thus the mothers could be transferred to specialized centres before giving 
Table 1: Neonatal mortality rates in urban and rural areas of Shenyang during 1997-2014

\begin{tabular}{|c|c|c|c|c|c|c|c|c|c|}
\hline \multirow{2}{*}{ Year } & \multicolumn{3}{|c|}{ Urban and rural areas } & \multicolumn{3}{|c|}{ Urban areas ${ }^{\dagger}$} & \multicolumn{3}{|c|}{ Rural areas ${ }^{\dagger}$} \\
\hline & Live births & No. & Rate* & Live births & No. & Rate* & Live births & No. & Rate* \\
\hline 1997 & 48628 & 368 & 7.57 & 30022 & 197 & 8.49 & 18606 & 171 & 9.19 \\
\hline 1998 & 45881 & 348 & 7.58 & 27943 & 195 & 8.41 & 17938 & 153 & 8.53 \\
\hline 1999 & 42474 & 300 & 7.06 & 26416 & 167 & 7.87 & 16058 & 133 & 8.28 \\
\hline 2000 & 44245 & 319 & 7.21 & 28723 & 175 & 8.18 & 15522 & 144 & 9.28 \\
\hline 2001 & 43244 & 301 & 6.96 & 28306 & 158 & 7.88 & 14938 & 143 & 9.57 \\
\hline 2002 & 46163 & 312 & 6.76 & 30367 & 161 & 7.05 & 15796 & 151 & 9.56 \\
\hline 2003 & 36015 & 259 & 7.19 & 15400 & 73 & 6.43 & 20615 & 186 & 9.02 \\
\hline 2004 & 46240 & 260 & 5.62 & 28473 & 137 & 7.02 & 17767 & 123 & 6.92 \\
\hline 2005 & 52972 & 306 & 5.78 & 22674 & 102 & 6.35 & 30298 & 204 & 6.73 \\
\hline 2006 & 52237 & 302 & 5.78 & 22896 & 85 & 5.20 & 29341 & 217 & 7.40 \\
\hline 2007 & 61111 & 345 & 5.65 & 30251 & 114 & 5.42 & 30860 & 231 & 7.49 \\
\hline 2008 & 59163 & 224 & 3.79 & 30255 & 73 & 4.30 & 28908 & 151 & 5.22 \\
\hline 2009 & 59232 & 179 & 3.02 & 32488 & 71 & 3.26 & 26744 & 108 & 4.04 \\
\hline 2010 & 57523 & 204 & 3.55 & 34823 & 86 & 3.36 & 22700 & 118 & 5.20 \\
\hline 2011 & 58303 & 197 & 3.38 & 37919 & 90 & 3.14 & 20384 & 107 & 5.25 \\
\hline 2012 & 69469 & 163 & 2.35 & 49121 & 84 & 2.69 & 20348 & 79 & 3.88 \\
\hline 2013 & 67856 & 183 & 2.70 & 49533 & 103 & 2.93 & 18323 & 80 & 4.37 \\
\hline 2014 & 79827 & 149 & 1.87 & 61002 & 83 & 2.39 & 18825 & 66 & 3.51 \\
\hline Total & 970583 & 4719 & 4.86 & 586612 & 2154 & 3.67 & 383971 & 2565 & 6.68 \\
\hline
\end{tabular}

*Neonatal mortality rates were expressed as per 1000 live births.

Urban areas included five districts (He Pin, Shen He, Da Dong, Huang Gu, and Tie Xi); Rural areas included eight districts (Liao Zhong, Kang Pin, Fa Ku, Xin Ming, Shen Bei, Hun Nan, Yu Hong, and Su Jiatun).

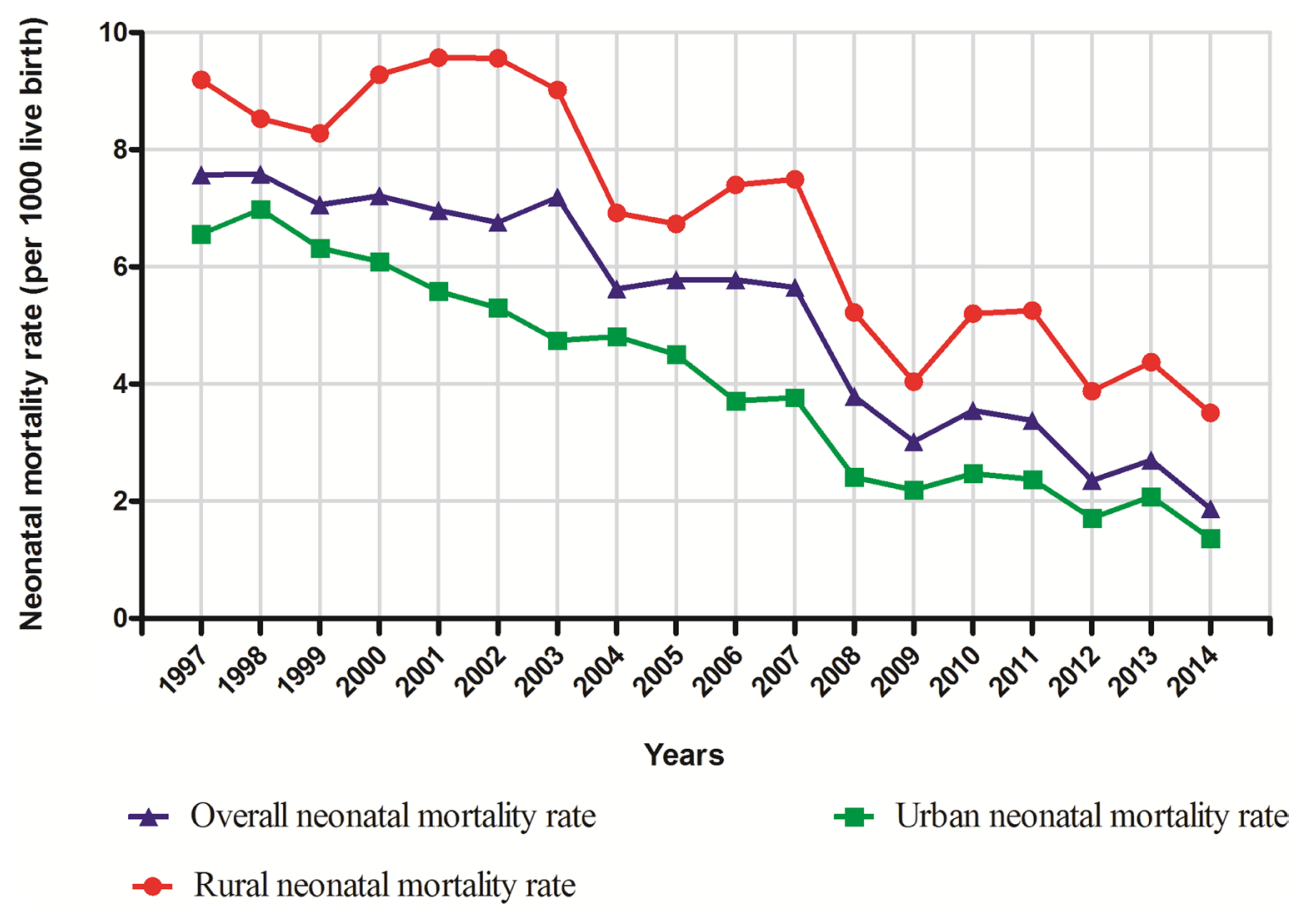

Figure 1: Trends in neonatal mortality rate (per 1000 live births) by areas in Shenyang, 1997-2014. 
Table 2: Trends in neonatal mortality rate in Shenyang in 1997-2014

\begin{tabular}{|c|c|c|c|c|c|c|c|}
\hline \multirow{2}{*}{ Cause of death } & \multicolumn{2}{|c|}{1997} & \multicolumn{2}{|c|}{2014} & \multirow{2}{*}{$\mathrm{PC}^{\dagger}(\%)$} & \multirow{2}{*}{$\operatorname{APC}^{\dagger}(\%)$} & \multirow{2}{*}{$95 \% \mathrm{CI}$} \\
\hline & Case & Rate $^{*}$ & Case & Rate $^{*}$ & & & \\
\hline Overall & 368 & 7.57 & 149 & 1.87 & -75.34 & -7.04 & $-8.60,-5.45$ \\
\hline Infectious and parasitic diseases & 1 & 0.02 & 6 & 0.08 & 265.50 & -2.37 & $-7.41,2.94$ \\
\hline Congenital malformations & 121 & 2.49 & 21 & 0.26 & -89.43 & -9.97 & $-12.04,-7.84$ \\
\hline Diseases of the perinatal period & 201 & 4.13 & 95 & 1.19 & -71.21 & -6.04 & $-7.20,-4.81$ \\
\hline $\begin{array}{l}\text { Diseases of the nervous system and } \\
\text { sense organs }\end{array}$ & 1 & 0.02 & 2 & 0.03 & 21.83 & -6.67 & $-14.44,1.81$ \\
\hline Diseases of the respiratory system & 31 & 0.64 & 11 & 0.14 & -78.38 & -8.52 & $-12.31,-4.55$ \\
\hline Disease of the digestive system & 0 & 0 & 5 & 0.06 & N/A & 1.11 & $-7.70,10.76$ \\
\hline Accident & 5 & 0.10 & 2 & 0.03 & -75.63 & -3.63 & $-11.84,5.34$ \\
\hline Others ${ }^{\S}$ & 8 & 0.16 & 8 & 0.10 & -39.08 & -6.01 & $-12.92,1.44$ \\
\hline
\end{tabular}

APC, annual percent change; CI, confidence interval; N/A, not available; PC, percent change.

*Neonatal mortality rates were expressed as per 1000 live births.

'Percent change and annual percent change between 1997 and 2014 was calculated by the neonatal mortality rate.

${ }^{\S}$ Others including endocrine, nutritional and metabolic diseases, blood and hematopoietic organ diseases, circulatory system diseases, urinary system diseases, leukemia and other neoplasms, and unknown or missing causes of deaths.

birth [6, 8]. Moreover, the development of treatments for manageable disorders, such as congenital malformations of the heart, was improved upon considerably, which increases the survival rates of patients with these disorders $[9,10]$. Additionally, since the difference between the development of urban and rural areas, the APC of congenital malformations and diseases of the perinatal period of urban areas was smaller than that of rural areas.

Among selective causes of neonatal mortality, except for preterm birth and low birth weight which belong to the diseases of perinatal period, birth asphyxia was the leading cause of neonatal mortality in urban and rural areas (Table 4). Previous studies suggested that decreasing neonatal mortality of birth asphyxia mainly resulted from high rates of hospital delivery [7]. Compared to hospital delivery, home delivery, mainly assisted by a village doctor or midwife without sufficient knowledge and skill, is strongly linked with poverty, poor transport connection or superstition [7]. In contrast to the $1.5 \%$ of neonatal deaths that were attributed to home delivery in urban areas, almost $25 \%$ of neonatal deaths resulted from home delivery in Chinese rural areas between 2003 and 2006. Therefore, during the past decades, the Chinese government has been implementing a subsidy project to allow rural pregnant women to give birth in hospitals; thereby, reducing the neonatal mortality through improving rural hospital delivery rates [11]. Furthermore, the considerable decrease in the neonatal mortality of pneumonia during the observation period could be attributed to substantial improvements in the medical treatment administered in neonatal intensive care units, and to improved care during the perinatal period [12].

Compared with the neonatal mortality rates in China in 1997 (24.4 per 1000 live births), which were provided by UNICEF [13], the rates were significantly lower both in Shenyang's urban areas (3.67 per 1000 live births) and rural areas (6.68 per 1000 live births). Although these rates were considerably lower than those of some Asian countries (e.g., India with 49 per 1000 live births), they were higher than the neonatal mortality rates of Korea (1.8 per 1000 live births) and Japan (2 per 1000 live births) [13]. During the past two decades, according to a UNICEF report published recently, the neonatal mortality rates of urban areas in 2014 (2.39 per 1000 live births) were slightly higher than that of the Republic of Korea (1.7 per 1000 live births).

The major strengthen of the present study was the valuable evidence of time trends of neonatal mortality from one the most important developing countries, China. Given the high reliability of the data published by the Shenyang Women and Children Health Care Centre, the results of this study showed appropriate representativeness. Furthermore, the long observation period provided the possibility to describe the time trends of different causes of neonatal death. Several limitations of this study also should be acknowledged. First, limited by the access of data, we could not present the rate and trends of early neonatal mortality, number of neonatal deaths under age 7 days per 1,000 live births. Moreover, because there was no case of neonatal death of several causes, we could not calculate 
Table 3: Trends in neonatal mortality rate in Shenyang by urban and rural areas in 1997-2014

\begin{tabular}{|c|c|c|c|c|c|c|c|c|c|c|c|c|c|c|}
\hline \multirow{3}{*}{$\begin{array}{c}\text { Cause of } \\
\text { death }\end{array}$} & \multicolumn{6}{|c|}{ Urban area $a^{\ddagger}$} & \multirow{3}{*}{$95 \%$ CI } & \multicolumn{6}{|c|}{ Rural area } & \multirow{3}{*}{$95 \% \mathrm{CI}$} \\
\hline & \multicolumn{2}{|c|}{1997} & \multicolumn{2}{|c|}{2014} & \multirow{2}{*}{$\begin{array}{l}\mathbf{P C}^{\dagger} \\
(\%)\end{array}$} & \multirow{2}{*}{$\begin{array}{c}\mathbf{A P C}^{\dagger} \\
(\%)\end{array}$} & & \multicolumn{2}{|c|}{1997} & \multicolumn{2}{|c|}{2014} & \multirow{2}{*}{$\begin{array}{l}\mathbf{P C}^{\dagger} \\
(\%)\end{array}$} & \multirow{2}{*}{$\begin{array}{c}\mathrm{APC}^{\dagger} \\
\mathbf{( \% )}\end{array}$} & \\
\hline & Case & Rate $^{*}$ & Case & Rate $^{*}$ & & & & Case & Rate $^{*}$ & Case & Rate $^{*}$ & & & \\
\hline Overall & 197 & 4.05 & 83 & 1.04 & -74.33 & -8.52 & $\begin{array}{l}-9.67 \\
-7.34\end{array}$ & 171 & 3.52 & 66 & 0.83 & -76.49 & -5.26 & $\begin{array}{l}-6.85 \\
-3.64\end{array}$ \\
\hline $\begin{array}{l}\text { Infectious } \\
\text { and parasitic } \\
\text { diseases }\end{array}$ & 1 & 0.02 & 4 & 0.05 & 143.67 & -5.07 & $\begin{array}{c}-12.41 \\
2.90\end{array}$ & 0 & 0 & 2 & 0.03 & N/A & 1.61 & $\begin{array}{c}-4.24 \\
7.83\end{array}$ \\
\hline $\begin{array}{l}\text { Congenital } \\
\text { malfor } \\
\text { mations }\end{array}$ & 79 & 1.62 & 9 & 0.11 & -93.06 & -12.89 & $\begin{array}{l}-14.90 \\
-10.83\end{array}$ & 146 & 3.00 & 52 & 0.65 & -78.30 & -5.54 & $\begin{array}{l}-6.93 \\
-4.13\end{array}$ \\
\hline $\begin{array}{l}\text { Disease of } \\
\text { the perinatal } \\
\text { period }\end{array}$ & 97 & 1.99 & 55 & 0.69 & -65.46 & -6.67 & $\begin{array}{l}-8.04 \\
-5.27\end{array}$ & 104 & 2.14 & 40 & 0.50 & -76.57 & -5.16 & $\begin{array}{l}-6.36 \\
-3.95\end{array}$ \\
\hline $\begin{array}{l}\text { Diseases of } \\
\text { the nervous } \\
\text { system and } \\
\text { sense organs }\end{array}$ & 0 & 0 & 0 & 0 & N/A & -9.88 & $\begin{array}{c}-18.08 \\
-0.86\end{array}$ & 1 & 0.02 & 1 & 0.01 & -39.08 & -1.29 & $\begin{array}{c}-8.16 \\
6.09\end{array}$ \\
\hline $\begin{array}{l}\text { Diseases } \\
\text { of the } \\
\text { respiratory } \\
\text { system }\end{array}$ & 15 & 0.31 & 6 & 0.08 & -75.63 & -8.88 & $\begin{array}{c}-13.95 \\
-3.51\end{array}$ & 16 & 0.33 & 5 & 0.06 & -80.96 & -7.60 & $\begin{array}{c}-11.81 \\
-3.18\end{array}$ \\
\hline $\begin{array}{l}\text { Disease of } \\
\text { the digestive } \\
\text { system }\end{array}$ & 0 & 0 & 3 & 0.04 & N/A & -2.47 & $\begin{array}{c}-15.02 \\
11.94\end{array}$ & 0 & 0 & 2 & 0.03 & N/A & -2.27 & $\begin{array}{c}-9.84 \\
5.92\end{array}$ \\
\hline Accident & 2 & 0.04 & 2 & 0.03 & -39.08 & -4.78 & $\begin{array}{c}-13.63 \\
4.97\end{array}$ & 3 & 0.06 & 0 & 0 & -100.00 & 0.40 & $\begin{array}{c}-6.98 \\
8.36\end{array}$ \\
\hline Others ${ }^{\S}$ & 3 & 0.06 & 4 & 0.05 & -18.78 & -5.54 & $\begin{array}{c}-12.48 \\
1.95\end{array}$ & 5 & 0.10 & 4 & 0.05 & -51.27 & -4.30 & $\begin{array}{c}-11.71 \\
3.72\end{array}$ \\
\hline
\end{tabular}

APC, annual percent change; CI, confidence interval; N/A, not available; PC, percent change.

* Neonatal mortality rates were expressed as per 1000 live births.

†Percent change and annual percent change between 1997 and 2014 was calculated by the neonatal mortality rate.

tUrban areas included five districts (He Pin, Shen He, Da Dong, Huang Gu, and Tie Xi); Rural areas included eight districts (Liao Zhong, Kang Pin, Fa Ku, Xin Ming, Shen Bei, Hun Nan, Yu Hong, and Su Jiatun).

${ }^{\S}$ Others including endocrine, nutritional and metabolic diseases, blood and hematopoietic organ diseases, circulatory system diseases, urinary system diseases, leukemia and other neoplasms, and unknown or missing causes of deaths.

the PC of these causes (Table 3). Finally, compared to many developed countries, the Shenyang Women and Children Health Care Centre started collecting information in 1992 and were vulnerable to several common technical problems that could jeopardize the quality of the data collected. During the approximate two decades of centre's operation, our centre, as well as the infrastructural development of China, was experiencing a transition. Additionally, though autopsy is the gold standard to confirm the cause of death of neonates, a relatively low rate of autopsy was observed in several developed countries as well as in China. Nevertheless, we have yielded high consistency between autopsy and determination of causes of neonatal deaths which may partly improve the quality of this study.

In conclusion, the neonatal mortality in Shenyang significantly decreased during the time period of 1997 to 2014. The MDG-4 of neonatal death was achieved in urban areas but not rural areas. This issue could be partly attributed to the different rates and time trends of the several categories of neonatal death. The findings of the present study are important for policy makers to gain a better understanding of the fluctuation of neonatal mortality and to take measures to maintain the recent decreasing trends of these causes, thereby reducing the public health burden in China. 
Table 4: The relative contributions of each death causes by urban and rural areas in Shenyang, 1997-2014

\begin{tabular}{|c|c|c|c|c|c|c|c|c|c|c|}
\hline \multirow{3}{*}{ Cause of death } & \multicolumn{4}{|c|}{ Urban and Rural areas } & \multirow{2}{*}{\multicolumn{2}{|c|}{$\begin{array}{c}\text { Urban areas } \\
\text { Decreasing trend }\end{array}$}} & \multicolumn{4}{|c|}{ Rural areas } \\
\hline & \multicolumn{2}{|c|}{ Decreasing trend } & \multicolumn{2}{|c|}{ Increasing trend } & & & \multicolumn{2}{|c|}{ Decreasing trend } & \multicolumn{2}{|c|}{ Increasing trend } \\
\hline & $\beta$ & $\begin{array}{l}\text { Contribution } \\
\text { rate }(\%)\end{array}$ & $\boldsymbol{\beta}$ & $\begin{array}{l}\text { Contribution } \\
\text { rate }(\%)\end{array}$ & $\beta$ & $\begin{array}{l}\text { Contribution } \\
\text { rate }(\%)\end{array}$ & $\beta$ & $\begin{array}{c}\text { Contribution } \\
\text { rate }(\%)\end{array}$ & $\boldsymbol{\beta}$ & $\begin{array}{l}\text { Contribution } \\
\text { rate }(\%)\end{array}$ \\
\hline $\begin{array}{l}\text { Infectious and } \\
\text { parasitic diseases }\end{array}$ & -0.024 & 5.36 & - & - & -0.052 & 8.86 & - & - & 0.016 & 80.00 \\
\hline $\begin{array}{l}\text { Congenital } \\
\text { malformations }\end{array}$ & -0.105 & 23.44 & - & - & 0.138 & 23.51 & -0.067 & 24.01 & - & - \\
\hline $\begin{array}{l}\text { Diseases of the } \\
\text { perinatal period }\end{array}$ & -0.062 & 13.84 & & & -0.069 & 11.75 & -0.053 & 18.99 & & \\
\hline $\begin{array}{l}\text { Diseases of the } \\
\text { nervous system } \\
\text { and sense organs }\end{array}$ & -0.069 & 15.40 & - & - & -0.104 & 17.71 & -0.013 & 4.66 & - & - \\
\hline $\begin{array}{l}\text { Diseases of the } \\
\text { respiratory system }\end{array}$ & -0.089 & 19.87 & - & - & -0.093 & 15.84 & -0.079 & 28.32 & - & - \\
\hline $\begin{array}{l}\text { Disease of the } \\
\text { digestive system }\end{array}$ & - & - & 0.011 & 100.00 & -0.025 & 4.26 & -0.023 & 8.24 & - & - \\
\hline Accident & -0.037 & 8.26 & - & - & -0.049 & 8.35 & - & - & 0.004 & 20.00 \\
\hline Others $\S$ & -0.062 & 13.84 & - & - & -0.057 & 9.71 & -0.044 & 15.77 & - & - \\
\hline
\end{tabular}

\$Others including endocrine, nutritional and metabolic diseases, blood and hematopoietic organ diseases, circulatory system diseases, urinary system diseases, leukemia and other neoplasms, and unknown or missing causes of deaths.

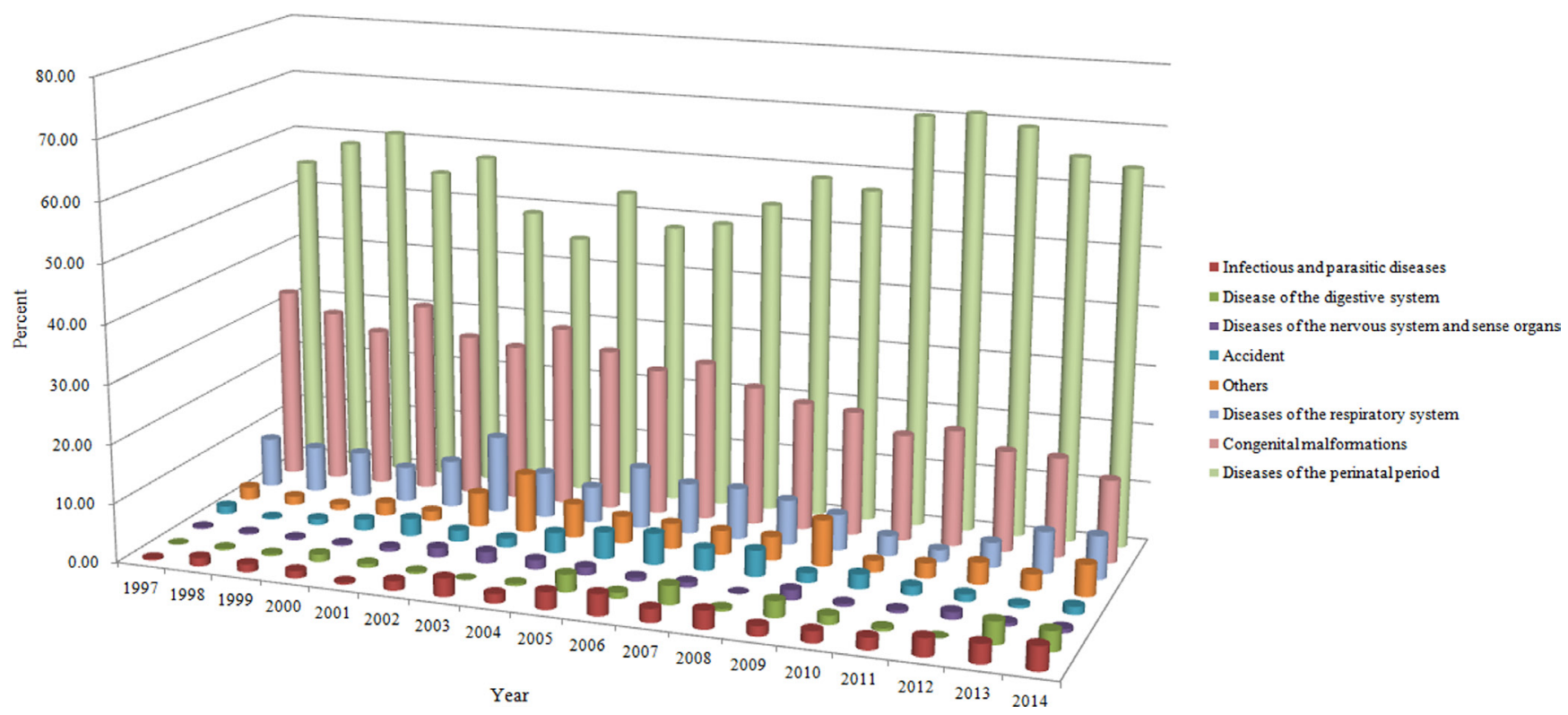

Figure 2: The proportions of categories of causes of neonatal mortality in urban and rural areas, $1997-2014$. 
Table 5: Trends in neonatal mortality rate of selective causes in Shenyang in 1997-2014

\begin{tabular}{|c|c|c|c|c|c|c|c|}
\hline \multirow{2}{*}{ Selective causes of death } & \multicolumn{2}{|c|}{1997} & \multicolumn{2}{|c|}{2014} & \multirow{2}{*}{$\mathrm{PC}^{\dagger}(\%)$} & \multirow{2}{*}{$\operatorname{APC}^{\dagger}(\%)$} & \multirow{2}{*}{$95 \% \mathrm{CI}$} \\
\hline & Case & Rate $^{*}$ & Case & Rate $^{*}$ & & & \\
\hline Septicemia & 1 & 0.02 & 6 & 0.08 & 265.50 & -2.08 & $-7.53,3.69$ \\
\hline Pneumonia & 29 & 0.60 & 8 & 0.10 & -83.20 & -7.87 & $-11.51,-4.09$ \\
\hline Congenital heart disease & 38 & 0.78 & 11 & 0.14 & -82.37 & -7.32 & $-9.65,-4.93$ \\
\hline Preterm birth and low birth weight & 77 & 1.58 & 66 & 0.83 & -47.79 & -2.47 & $-4.31,-0.59$ \\
\hline Birth asphyxia & 89 & 1.83 & 20 & 0.25 & -86.31 & -11.04 & $-11.98,-10.09$ \\
\hline Intracranial hemorrhage of the newborn & 28 & 0.58 & 3 & 0.04 & -93.47 & -10.68 & $-13.30,-7.99$ \\
\hline Accidental asphyxia & 5 & 0.10 & 2 & 0.03 & -75.63 & -3.63 & $-11.09,4.45$ \\
\hline
\end{tabular}

APC, annual percent change; CI, confidence interval; PC, percent change.

* Neonatal mortality rates were expressed as per 1000 live births.

†Percent change and annual percent change between 1997 and 2014 was calculated by the neonatal mortality rate.

Table 6: Trends in neonatal mortality rate of selective causes in Shenyang by urban and rural area in 1997-2014

\begin{tabular}{|c|c|c|c|c|c|c|c|c|c|c|c|c|c|c|}
\hline \multirow{3}{*}{$\begin{array}{l}\text { Selective } \\
\text { cause of } \\
\text { death }\end{array}$} & \multicolumn{6}{|c|}{ Urban area } & \multicolumn{7}{|c|}{ Rural area } & \multirow{3}{*}{$\begin{array}{c}95 \% \\
\text { CI }\end{array}$} \\
\hline & \multicolumn{2}{|c|}{1997} & \multicolumn{2}{|c|}{2014} & \multirow{2}{*}{$\begin{array}{l}\mathrm{PC}^{\dagger} \\
(\%)\end{array}$} & \multirow{2}{*}{$\begin{array}{c}\mathbf{A P C}^{\dagger} \\
(\%)\end{array}$} & \multirow[t]{2}{*}{$95 \% \mathrm{CI}$} & \multicolumn{2}{|c|}{1997} & \multicolumn{2}{|c|}{2014} & \multirow{2}{*}{$\begin{array}{l}\mathbf{P C}^{\dagger} \\
(\%)\end{array}$} & \multirow{2}{*}{$\begin{array}{c}\mathbf{A P C}^{\dagger} \\
(\%)\end{array}$} & \\
\hline & Case & Rate $^{*}$ & Case & Rate $^{*}$ & & & & Case & Rate $^{*}$ & Case & Rate $^{*}$ & & & \\
\hline Septicemia & 1 & 0.03 & 4 & 0.07 & 96.86 & -5.07 & $\begin{array}{c}-12.97, \\
3.55\end{array}$ & 0 & 0 & 2 & 0.11 & N/A & 1.61 & $\begin{array}{c}-4.24 \\
7.83\end{array}$ \\
\hline Pneumonia & 13 & 0.43 & 6 & 0.10 & -77.29 & -7.41 & $\begin{array}{c}-12.75 \\
-1.75\end{array}$ & 16 & 0.86 & 2 & 0.11 & -87.65 & -7.78 & $\begin{array}{c}-11.42 \\
-3.99\end{array}$ \\
\hline $\begin{array}{l}\text { Congenital } \\
\text { heart } \\
\text { disease }\end{array}$ & 21 & 0.70 & 4 & 0.07 & -90.63 & -10.86 & $\begin{array}{c}-13.47 \\
-8.18\end{array}$ & 17 & 0.91 & 7 & 0.37 & -59.30 & -3.34 & $\begin{array}{l}-6.17 \\
-0.43\end{array}$ \\
\hline $\begin{array}{l}\text { Preterm } \\
\text { birth and } \\
\text { low birth } \\
\text { weight }\end{array}$ & 31 & 1.03 & 41 & 0.67 & -34.91 & -2.66 & $\begin{array}{l}-5.11 \\
-0.16\end{array}$ & 46 & 2.47 & 25 & 1.33 & -46.28 & -1.88 & $\begin{array}{c}-3.94 \\
0.22\end{array}$ \\
\hline $\begin{array}{l}\text { Birth } \\
\text { asphyxia }\end{array}$ & 47 & 1.57 & 11 & 0.18 & -88.48 & -11.31 & $\begin{array}{c}-13.17 \\
-9.41\end{array}$ & 42 & 2.26 & 9 & 0.48 & -78.82 & -10.68 & $\begin{array}{c}-12.56 \\
-8.77\end{array}$ \\
\hline $\begin{array}{l}\text { Intracranial } \\
\text { hemorrhage } \\
\text { of the } \\
\text { newborn }\end{array}$ & 14 & 0.47 & 1 & 0.02 & -96.48 & -10.68 & $\begin{array}{c}-14.94 \\
-6.22\end{array}$ & 14 & 0.75 & 2 & 0.11 & -85.88 & -10.95 & $\begin{array}{l}-14.47, \\
-7.29\end{array}$ \\
\hline $\begin{array}{l}\text { Accidental } \\
\text { asphyxia }\end{array}$ & 2 & 0.07 & 2 & 0.03 & -50.76 & -4.02 & $\begin{array}{c}-13.49 \\
6.49\end{array}$ & 3 & 0.16 & 0 & 0 & -100.00 & 0.30 & $\begin{array}{c}-5.68 \\
6.66\end{array}$ \\
\hline
\end{tabular}

PC, percent change; APC, annual percent change; CI, confidence interval.

* Neonatal mortality rates were expressed as per 1000 live births.

†Percent change and annual percent change between 1997 and 2014 was calculated by the neonatal mortality rate.

*Urban areas included five districts (He Pin, Shen He, Da Dong, Huang Gu, and Tie Xi); Rural areas included eight districts (Liao Zhong, Kang Pin, Fa Ku, Xin Ming, Shen Bei, Hun Nan, Yu Hong, and Su Jiatun). 


\section{MATERIALS AND METHODS}

\section{Study population}

We defined neonatal mortality as death of the neonates from the day of birth through 28 days after birth, and we calculated the total number of deaths among all neonates during the study period [14]. Live birthneonate death data files were collected by the Shenyang Women and Children Health Care Centre which was a comprehensive care institution and the Centre of Women and Children's Health Care Guidance in the city of Shenyang since 1987. Its catchment area includes five urban districts (He Pin, Shen He, Da Dong, Huang Gu, and Tie $\mathrm{Xi}$ ) and eight rural districts (Liao Zhong, Kang Pin, Fa Ku, Xin Ming, Shen Bei, Hun Nan, Yu Hong, and Su Jiatun), with a total of 8.1 million inhabitants.

\section{Data source}

The main procedure for gathering data is passive notification of cases, both by public or private hospitals/ clinics. The data concerning the cause of neonatal deaths were classified according to the International Classification of Diseases (ICD)-10 codes. We obtained the data regarding neonatal deaths between January 1, 1997 and December 31,2014 . The main categories of neonatal mortality were the following: infectious and parasitic diseases; congenital malformations; diseases of the perinatal period, diseases of the nervous system and sense organs; diseases of the respiratory system; diseases of the digestive system; accident; and other cause of neonatal death, for example endocrine, nutritional and metabolic diseases; blood and hematopoietic organ diseases; circulatory system diseases; urinary system diseases; and leukaemia and other neoplasms [6]. The unknown or missing causes of deaths were also officially classified into other causes of deaths (6). The unknown or missing cause's rates were less than $8 \%$ through the seventeen years.

\section{Statistical analysis}

Neonatal mortality rates were calculated for seventeen 1-year time intervals from 1997 to 2014. The annual percentage change (APC) for neonatal mortality rates was used to quantify the time trends $[15,16]$. A regression line was fitted to the natural logarithm of the rates, weighted by the number of cases, i.e. $y=\alpha+\beta x+\varepsilon$, where $y=\ln ($ rate $)$ and $\mathrm{x}=$ calendar year, and then the APC was calculated as $100 \times\left(\mathrm{e}^{\beta}-1\right)$. The $95 \%$ confidence interval $(\mathrm{CI})$ of the APC was calculated by the methods for population-based cancer statistics recommended by the National Cancer Institute [17]. Additionally, we calculated the relative contributions for rate changes to determine the contributions made to the overall trend from categories of death causes [17].
This is done by calculating the percent contribution of each negative regression coefficient to the sum of the negative coefficient, and similarly, percents can be calculated for each positive coefficient [17]. If the overall trend is decreasing, then it is assumed that the percentages for the subgroups with a negative regression coefficient represent their relative contribution to the decreasing trend and are, in effect, a part of the decreasing trend [17]. When grouped by selective causes of neonatal mortality, we only presented the results of the causes that did not have zero death in overall areas during 1997-2014 (septicemia, pneumonia, congenital heart disease, preterm birth and low birth weight, birth asphyxia, intracranial hemorrhage of the newborn, and accidental asphyxia). All analyses were conducted using SPSS for Windows (version 17, SPSS Inc, Chicago, IL, USA). All statistical tests were two-sided, and $P$-values less than 0.05 were considered statistically significant.

\section{ACKNOWLEDGMENTS}

Q-JW, L-LL, JL, CZ, and Y-HH designed research; Q-JW and CZ conducted research; Q-JW and CZ analyzed data; Q-JW and CZ wrote the draft; All authors read, reviewed and approved the final manuscript. Q-JW and L-LL had primary responsibility for final content.

Qi-Jun $\mathrm{Wu}$ and $\mathrm{Li}-\mathrm{Li} \mathrm{Li}$ contributed equally to this work.

\section{GRANT SUPPORT}

This study was supported by the Shenyang science and technology project (F13-220-9-40 for $\mathrm{Li}-\mathrm{Li} \mathrm{Li}$ ). Qi-Jun $\mathrm{Wu}$ was supported by the Fogarty International Clinical Research Scholars and Fellows Support Center at the Vanderbilt Institute for Global Health, funded by the Fogarty International Center, NIH, through an R24 Training Grant (D43 TW008313 to Xiao-Ou Shu).

\section{CONFLICTS OF INTEREST}

The authors declare no competing financial interests.

\section{REFERENCES}

1. United Nations Children's Fund. Committing to Child Survival: A Promise Renewed-Progress Report 2015. Available from: http://www.unicef.org/publications/ index_83078. Accessed January 20, 2015.

2. World Health Organization. MDG 4: reduce child mortality. Available from: http://www.who.int/topics/millennium development_goals/child_mortality/en/. Accessed January 20, 2015.

3. Conley D, Springer KW. Welfare state and infant mortality. AJS. 2001; 107:768-807. 
4. Neonatal and Perinatal Mortality: Country, Regional and Global Estimates. WHO-Geneva. 2006:20.

5. World Health Organization. Global Health Observatory Data Repository. Available from: http:/www.who.int/ topics/millennium_development_goals/child_mortality/en/. Accessed January 20, 2015.

6. Waldhor T, Vutuc C, Haidinger G, Mittlbock M, Kirchner L, Wald M. Trends in infant mortality in Austria between 1984 and 2002. Wien Klin Wochenschr. 2005; 117:548-553.

7. Yanping W, Lei M, Li D, Chunhua H, Xiaohong L, Mingrong L, Guangxuan Z, Jun Z, Juan L. A study on rural-urban differences in neonatal mortality rate in China, 1996-2006. J Epidemiol Community Health. 2010; 64: 935-936.

8. Hohlagschwandtner M, Husslein P, Klebermass $\mathrm{K}$, Weninger M, Nardi A, Langer M. Perinatal mortality and morbidity. Comparison between maternal transport, neonatal transport and inpatient antenatal treatment. Arch Gynecol Obstet. 2001; 265:113-118.

9. Forrester MB, Merz RD. First-year mortality rates for selected birth defects, Hawaii, 1986-1999. Am J Med Genet A. 2003; 119A:311-318.

10. Frid C, Drott P, Otterblad OP, Sundelin C, Anneren G. Maternal and neonatal factors and mortality in children with Down syndrome born in 1973-1980 and 1995-1998. Acta Paediatr. 2004; 93: 106-112.
11. Martin JA, Kung HC, Mathews TJ, Hoyert DL, Strobino DM, Guyer B, Sutton SR. Annual summary of vital statistics: 2006. Pediatrics. 2008; 121:788-801.

12. Nakamura Y, Nagai M, Yanagawa H. A characteristic change in infant mortality rate decrease in Japan. Public Health. 1991; 105:145-151.

13. United Nations Children's Fund. Country statistics. Available from: http://www.unicef.org/statistics. Accessed January 20, 2015.

14. Gregory EC, MacDorman MF, Martin JA. Trends in fetal and perinatal mortality in the United States, 2006-2012. NCHS Data Brief. 2014:1-8.

15. Krzyzak M, Maslach D, Piotrowska K, Charkiweicz AE, Szpak A, Karczewski J. Perinatal mortality in urban and rural areas in Poland in 2002-2012. Przegl Epidemiol. 2014; 68:675-679.

16. Wu QJ, Vogtmann E, Zhang W, Xie L, Yang WS, Tan YT, Gao J, Xiang YB. Cancer incidence among adolescents and young adults in urban Shanghai, 1973-2005. PLoS One. 2012; 7:e42607.

17. Hankey BF, Ries LA, Kosary CL, Feuer EJ, Merrill RM, Clegg LX, Edwards BK. Partitioning linear trends in ageadjusted rates. Cancer Causes Control. 2000; 11:31-35. 